\title{
A Soberania Alimentar e o Programa Nacional de Alimentação Escolar no município de Piracicaba (SP) - concepções e redefinições
}

\author{
Samira Gaiad Cibim de Camargo Bosquilia ${ }^{1}$ e Maria Angélica Penatti Pipitone ${ }^{2}$
}

O conceito de segurança alimentar surgiu após a II Guerra Mundial trazendo à tona a formulação de critérios ditos como essenciais para uma alimentação digna e correta para todos. Tal conceito serviu de base para discussões e propostas de movimentos sociais que resultaram na formulação do conceito de Soberania Alimentar, na década de 1990. A Soberania Alimentar apregoa que todos os indivíduos, comunidades, povos e países possuem o direito de definir suas próprias políticas da agricultura, do trabalho, do alimento e da terra. A presente pesquisa teve por objetivo analisar o conceito de Soberania Alimentar e suas implicações no âmbito da gestão do Programa Nacional de Alimentação Escolar (PNAE) no município de Piracicaba (estado de São Paulo). Para isso, foram realizadas pesquisas bibliográficas, análise documental e entrevistas semiestruturadas. Entre os resultados, foi possível verificar que o conceito de Soberania Alimentar é pouco explorado no desenvolvimento do PNAE, ainda que seja encontrado nas falas dos gestores e nos documentos do programa. O maior desafio do PNAE, de acordo com a pesquisa, resulta na dificuldade de coordenação dos muitos atores envolvidos na gestão do PNAE em torno da adoção dos princípios e práticas da Soberania Alimentar.

Palavras-chave: Soberania Alimentar; Alimentação Escolar; Agricultura Familiar.

\section{Food Sovereignty and the National School Feeding Program in the city of Piracicaba (São Paulo) - conceptions and redefinitions}

The concept of food security emerged after World War II, bringing up the formulation of criteria considered essential for a dignified and correct diet for population. This concept served as a basis for discussions and proposals of social movements, resulting in the formulation of the concept of Food Sovereignty in the 1990s. Food Sovereignty claims that all individuals, communities, peoples, and countries have the right to define their own agriculture, labor, food and land. The present research aimed at analyzing the concept of Food Sovereignty and its implications in the management of the National School Feeding Program (PNAE) in the city of Piracicaba (SP). For that, bibliographical research, documentary analysis, and semi-structured interviews were carried out. The results have shown that the concept of Food Sovereignty is little explored in the development of the PNAE, although it is found in the statements of managers and in documents of the Program. According to the results, the greater challenge of the PNAE is the difficulty of coordination of people involved in the management of PNAE concerning the adoption of principles and practices of Food Sovereignty.

\footnotetext{
${ }^{1}$ Mestre em Ecologia Aplicada pela Escola Superior de Agricultura "Luiz de Queiroz" - ESALQ, Universidade de São Paulo - USP. Endereço para correspondência: Av. Pádua Dias no 11, CEP: 13418-900, Piracicaba, SP, Brasil. Telefone: +55 (19) 3429-4225. E-mail: samira_gaiad@hotmail.com

2 Professora Livre Docente do Departamento de Economia, Administração e Sociologia, Escola Superior de Agricultura "Luiz de Queiroz" - ESALQ, Universidade de São Paulo - USP. E-mail: angelicapenatti@gmail.com
} 
Keywords: Food Sovereignty; School Feeding; Family Farming.

\section{INTRODUÇÃO E OBJETIVOS}

O direito à alimentação é considerado um direito humano imbuído em uma categoria do Pacto Internacional dos Direitos Econômicos, Sociais e Culturais, postulado em 1966, posteriormente à Declaração Universal dos Direitos Humanos. A Declaração Universal dos Direitos Humanos por sua vez, foi assinada em dezembro de 1948, pelos povos do mundo, por intermédio de seus chefes de Estado e governos em um momento em que a humanidade tomou consciência da barbárie que representou o Holocausto.

A Declaração Universal dos Direitos Humanos, embora não seja um documento com força de Lei foi adotado como base para a formulação de outros dois acordos, o Pacto Internacional dos Direitos Civis e Políticos de 1992 e o Pacto Internacional sobre os Direitos Econômicos, Sociais e Culturais de 1966 e já referido nesse texto.

Nesses documentos é latente a ideia de que cabe ao Estado respeitar, proteger e zelar pela capacidade dos indivíduos, família ou comunidades de produzir sua própria alimentação e/ou de obter a renda monetária suficiente para adquirir alimentos adequados. É também notória a importância e o direito dos seres humanos à alimentação adequada e saudável.

De acordo com Belik [1], esses pressupostos deram origem ao conceito de segurança alimentar e envolve a qualidade dos alimentos, uma vez que, a alimentação disponível para população não deve estar sujeita a contaminações, problemas de apodrecimento ou prazo fora da validade, pois a qualidade dos alimentos diz respeito à possibilidade da população consumir alimentos de forma digna e que sigam as normas de segurança alimentar e de higiene. Outro aspecto importante imbuído no conceito trata da regularidade do acesso aos alimentos, que é diferente de disponibilidade de alimentos, ou seja, os alimentos estão disponíveis, porém muitas populações pobres não têm acesso a eles, em função de diferentes motivos como falta de recursos, conflitos internos, ação de monopólios e entre outros.
Com o passar das décadas e com a produção do conhecimento na área, essa ideia foi se consolidando até que em 1996 durante a Cúpula Mundial de Alimentação foi apontado pela Via Campesina o conceito de Soberania Alimentar como uma nova forma de pensar que, considerava que um povo para ser livre, precisava ser soberano e que essa soberania passava diretamente pelo viés da alimentação. $O$ conceito foi ganhando contornos e em 2011 ganhou sua última definição:

O direito dos povos à alimentação saudável e culturalmente adequada produzida através de métodos sustentáveis, e seu direito de definir seus próprios sistemas agrícolas e alimentares. Desenvolver um modelo de produção agrícola sustentável, que favorece as comunidades e seu ambiente. A Soberania Alimentar coloca as aspirações, necessidades e estilos de vida daqueles que produzem, distribuem e consomem alimentos no coração dos sistemas alimentares e políticas alimentares à frente das demandas dos mercados e corporações [2].

Vale destacar que esse conceito destaca a importância da autonomia alimentar dos povos, respeitando a cultura e hábitos de cada país, assim como está associado à geração de emprego e à menor dependência das importações e flutuações de preços do mercado exterior ${ }^{[3]}$.

Neste sentido, é de extrema importância o reconhecimento de que a Soberania Alimentar representa o direito dos povos de definir suas próprias políticas e estratégias sustentáveis de produção, distribuição e consumo de alimentos, que garantam o direito à alimentação para toda a sua população, com base na pequena e média produção, respeitando a diversidade de culturas e crenças das comunidades [4].

É sabido que os modelos de produção praticados em especial na época da "Revolução Verde" durante as décadas de 1960 e 1970 já contradiziam os princípios básicos de Soberania Alimentar para com a população. Tais princípios iriam ganhar mais força e proporção em décadas posteriores, uma vez que, 
durante o período da referida Revolução Verde 3 surgiu a criação de novas práticas agropecuárias que incluíam o uso de sementes geneticamente modificadas, o uso excessivo de insumos químicos, tais como, fertilizantes e agrotóxicos e a mecanização intensiva da produção agrícola [5].

Tais práticas contribuíram, de fato, para o aumento da produção em massa e o desenvolvimento do agronegócio. Além disso, a mídia na época alardeava a ideia de que a "Revolução Verde" resolveria os problemas de pobreza e fome por meio da produção em escala. Porém, não foi isso o que aconteceu, pois ao mesmo tempo os novos sistemas alimentares ocasionaram o empobrecimento de milhões de produtores de alimentos em pequena escala, criando ondas cada vez maiores de pobreza e fome, além de contribuir para o êxodo rural e afetar diretamente a saúde das pessoas. Estima-se que há 1 bilhão de pessoas em insegurança alimentar, e simultaneamente existe abundância de alimentos, sendo que grande parte dos mesmos não são saudáveis e acarretam uma dieta irregular que está afetando a saúde de pelo menos 2 bilhões de pessoas, causando obesidade, doenças cardíacas, câncer, diabetes, entre outras doenças [ ${ }^{6}$.

Sendo assim, vale ressaltar que segundo Valente [7], a alimentação incorpora muitos outros aspectos que também precisam ser levados em conta, como por exemplo, amor, carinho, socialização, cultura, espiritualidade e religiosidade. Por isto, pode-se dizer que a definição do que é uma alimentação adequada não pode ser reduzida a de uma "ração" nutricionalmente balanceada, mas sim aquela que colabora para a construção de seres humanos saudáveis, conscientes de seus direitos e deveres, enquanto cidadãos do Brasil e do mundo.

Deste modo, promover a segurança alimentar $\mathrm{e}$ nutricional sustentável e o conceito da Soberania Alimentar, nesta perspectiva, é uma responsabilidade coletiva partilhada entre os setores público e privado, resultando na articulação de políticas, programas e ações capazes de garantir a realização do direito humano à alimentação para todos.

A partir disso, o presente trabalho pautou-se por verificar se o conceito de Soberania Alimentar está inserido no Programa de Alimentação Escolar

${ }^{3}$ Revolução Verde refere-se à invenção e disseminação de novas sementes e práticas agrícolas que permitiram um vasto aumento na produção agrícola a partir da década de 1950 nos Estados Unidos e na Europa e, nas décadas seguintes, em outros países. desenvolvido no âmbito das escolas públicas do município de Piracicaba (estado de São Paulo) e quais são as implicações do referido conceito na gestão e operacionalização do programa.

\section{Programa Nacional de Alimentação Escolar (PNAE)}

No Brasil, o Programa Nacional de Alimentação Escolar (PNAE) teve início no ano de 1954, porém antes do início de sua operacionalização no país, existiram grandes esforços para que o PNAE passasse a operar no país e tais acontecimentos datam seu início a partir de 1930.

Em 1930 o grande destaque foram os estudos realizados pelo médico e nutrólogo Josué de Castro, um dos maiores ativistas brasileiros da área que dedicou sua vida ao combate à fome e à desnutrição, sendo pioneiro na análise dos determinantes econômicos e sociais da fome.

A partir de 1945 foram criados inúmeros órgãos e entidades no campo da alimentação, que resultaram no surgimento, em 1954, do Programa Nacional de Alimentação Escolar.

Desde sua criação, o PNAE possuía um gerenciamento centralizado. Era gerenciado pela Fundação de Assistência ao Estudante (FAE), desde o planejamento de cardápios até a distribuição final dos alimentos pelo país. Contudo, no ano de 1994, o gerenciamento passou a ser descentralizado, mediante a Lei no 8.913 de 12/07/1994, que preconizou o convênio com os municípios e as Secretarias de Educação dos Estados e do Distrito Federal, que passará a se responsabilizar pelo atendimento aos alunos dos municípios que não aderiram à descentralização.

No ano de 1998, a transferência de recursos financeiros passou a ser feita de forma automática pelo Fundo Nacional de Desenvolvimento da Educação (FNDE) que substituiu a Fundação de Assistência ao Estudante (FAE). Neste mesmo ano, houve a instituição do Conselho de Alimentação Escolar (CAE) em cada município brasileiro, com atribuições deliberativas, fiscalizadoras e de assessoramento, onde

É um amplo programa idealizado para aumentar a produção agrícola no mundo por meio do uso intensivo de insumos industriais, mecanização e redução do custo de manejo. 
possuem importante função de fiscalização da aplicação dos recursos destinados ao PNAE.

Já no ano de 2009, outro importante avanço ocorreu, ao ser institucionalizado que no mínimo 30\% do total de recursos repassados pelo FNDE, deveria ser utilizado na aquisição de gêneros alimentícios diretamente de agricultores familiares e dos empreendedores familiares rurais, detentores da Declaração de Aptidão ao Programa Nacional de Fortalecimento da Agricultura Familiar - DAP Física e/ou Jurídica.

Essa inovação foi estabelecida pela Lei da Agricultura Familiar no 11.326, de 24 de julho de 2006, e enquadrada no Programa Nacional de Fortalecimento da Agricultura Familiar - PRONAF.

O PNAE, nessa abordagem, pode ser considerado um espaço ou instrumento pedagógico, pois além de ser um programa fornecedor de alimentos, constitui um potencial espaço educativo eficiente para estimular a integração de temas relativos à nutrição, saúde e o currículo escolar ${ }^{[8]}$.

Pipitone [9] afirma que, entre professores, merendeiras e pais de alunos discussões evidenciando a função social e o significado dado à merenda escolar, valem mais do que aulas tradicionais apoiadas em cartazes coloridos sobre noções da boa alimentação.

Porém, para incluir a aprendizagem em saúde e nutrição como parte da cultura do serviço de alimentação escolar, toda a escola precisa sentir-se motivada a participar deste projeto. As atividades práticas executadas no serviço de alimentação escolar podem ser objeto das atividades pedagógicas executadas pelos professores e compartilhadas pela comunidade escolar.

No ano de 2013, o Programa Mundial de Alimentos (PMA) lançou o primeiro relatório sobre o "Estado de Alimentação Escolar no Mundo", que ofereceu um retrato e uma análise global da situação dos programas de alimentação escolar, tanto em países em desenvolvimento como em países desenvolvidos, além de revelar como os países se utilizam da merenda escolar como uma "rede de proteção" em tempos de crise [10].
De acordo com o citado relatório existem programas de alimentação escolar pelo mundo inteiro e a partir dos dados da referida pesquisa a necessidade primária é verificar como encontrar meios para melhorar a eficácia e eficiência dos programas já implementados. Outro ponto destacado é o fato de a cobertura dos programas de alimentação escolar ser menor em países onde há maior necessidade. Os países que possuem a maior cobertura de alimentação escolar são em primeiro lugar Índia com 114 milhões de beneficiários, Brasil em segundo lugar com 47 milhões de beneficiários, Estados Unidos em terceiro lugar com 45 milhões, seguido da China, em quarto lugar com 26 milhões.

O relatório aponta também, para os benefícios do chamado ciclo da sustentabilidade local, que é resultado do elo existente entre a alimentação escolar e a agricultura local.

No município de Piracicaba (SP), o PNAE teve início no ano de 1958. Em 2009 ocorreram mudanças na gestão com a introdução da terceirização de parte do fornecimento de alimentação escolar para ensino fundamental, médio e EJA.

Atualmente, o PNAE de Piracicaba atende cerca de 85.000 mil alunos e 218 escolas. A terceirização por sua vez, se encarrega de atender o maior número de escolas beneficiadas (Gráficos 1 e 2).

Gráfico 1. Número de alunos beneficiados pelo PNAE Piracicaba - dados de 2015

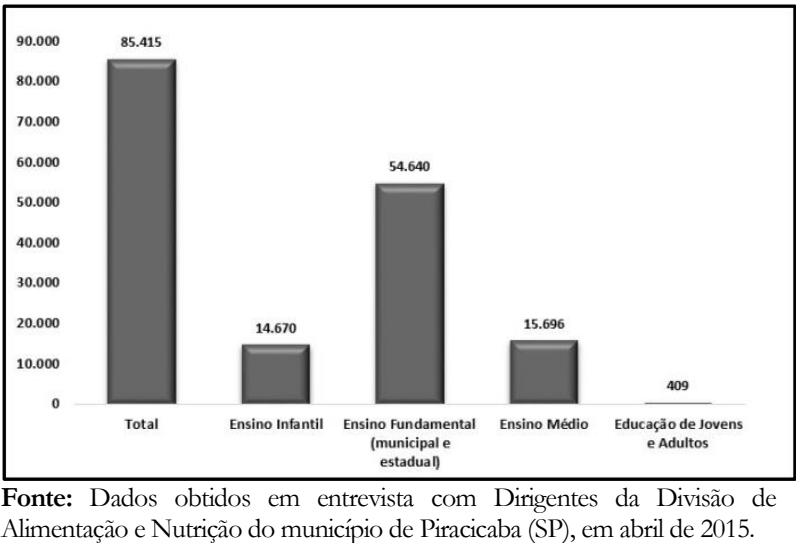


Gráfico 2. Número de escolas beneficiadas pelo PNAE Piracicaba de acordo com o modelo de gestão - dados de 2015

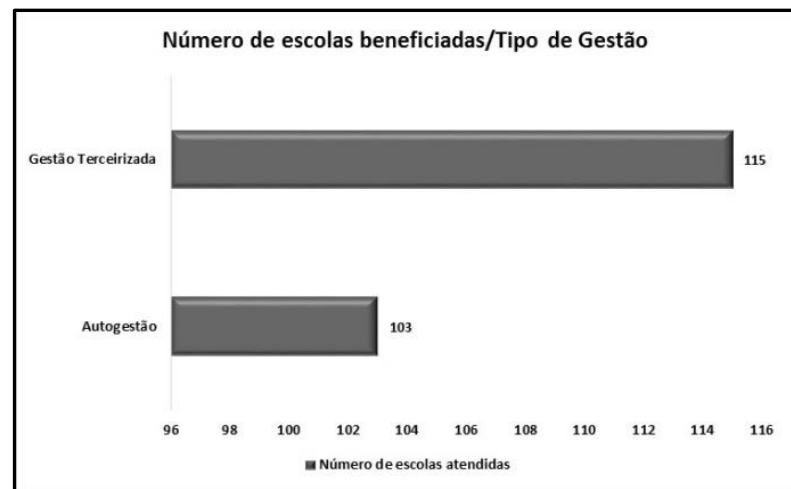

Fonte: Dados obtidos em entrevista com Dirigentes da Divisão de Alimentação e Nutrição do município de Piracicaba (SP), em abril de 2015.

\section{MATERIAL E MÉTODOS}

Com o objetivo de analisar o conceito de Soberania Alimentar e suas implicações no âmbito da gestão do programa de alimentação escolar do município de Piracicaba (SP) fez-se uso de metodologias qualitativas com ênfase na coleta de dados realizada a partir de pesquisa bibliográfica e de entrevistas semiestruturadas. A análise dos dados ocorreu por meio da análise documental e do conteúdo das entrevistas.

Partindo do princípio da escolha do documento, a análise do mesmo constitui-se numa atividade da pesquisa usada para descrever e interpretar o conteúdo de toda classe de documentos e textos. A análise deste conteúdo pode oscilar entre o rigor da suposta objetividade dos números e a fecundidade sempre questionada da subjetividade. Deste modo, as abordagens qualitativas têm sido utilizadas para atingir níveis de compreensão mais aprofundados dos fenômenos que se propõe a investigar [11].

Neste sentido, para este trabalho foi utilizada a técnica de análise de documentos apontada por Cellard ${ }^{[12]}$ que indica existirem algumas etapas que contribuem para uma análise preliminar dos documentos e que se aplicam em cinco dimensões, tais como, o contexto, o autor ou os autores, a autenticidade e confiabilidade do texto, a natureza do texto e os conceitos-chave e a lógica interna do texto. Para Cellard [12] especialmente a técnica de busca por palavras ou conceitos-chaves nos documentos, contribui para que seja possível verificar se baseado nos documentos selecionados há o alcance de resolução da hipótese proposta no início da pesquisa.

Nos documentos selecionados buscou-se, a princípio, a existência de indícios que revelassem se as premissas da Soberania Alimentar estavam (ou não) presentes nos documentos, bem como nas práticas desenvolvidas pelo Programa Nacional de Alimentação Escolar.

Deste modo, buscou-se pela presença de palavras-chave como: "Soberania Alimentar", "Sustentabilidade", "Respeito à Cultura e Hábitos Alimentares", "Alimentos Oriundos de Agricultura Familiar ou Sustentável".

Para isso, foram selecionados dois documentos que serviram de base para a análise documental. Um documento corresponde à Resolução no 26, de 17 de junho de 2013. Nele, há todo o histórico e fundamentação legal que dispõe sobre o atendimento da alimentação escolar aos alunos da educação básica no âmbito do Programa Nacional de Alimentação Escolar. Já o outro documento, corresponde a um texto disponível na home page da Secretaria Municipal de Educação no espaço reservado ao Serviço de Merenda Escolar (http:/ /www.educacao.piracicaba.sp.gov.br).

Neste trabalho desenvolveu-se a evolução histórica do PNAE, especificamente no município de Piracicaba (SP) com o auxílio de entrevistas e dados obtidos no portal da internet, da Secretaria Municipal de Educação de Piracicaba - SMEP (http://www.educacao.piracicaba.sp.gov.br).

As entrevistas semiestruturadas serviram, nesta pesquisa, como meio de coleta de dados, que igualmente à análise documental complementaram os resultados encontrados.

De forma subsidiária foram realizadas entrevistas prévias com duas profissionais da equipe técnica do Serviço de Merenda Escolar da Prefeitura Municipal de Piracicaba (SP) com o intuito consolidar hipóteses e atualizar os dados referentes ao PNAE, bem como para obter esclarecimentos sobre a funcionalidade e peculiaridades do PNAE, no município de Piracicaba (SP). 
Posteriormente, foi realizada entrevista semiestruturada com uma gestora da área da alimentação, também representante do Setor de Merenda Escolar de Piracicaba (SP).

Cada uma das duas técnicas do Serviço de Merenda Escolar por ocasião de entrevista teve oportunidade de apresentar informações acerca de um modelo de gestão do PNAE de Piracicaba, uma representou a autogestão realizada pela própria prefeitura do município e a outra apresentou dados sobre a gestão terceirizada da alimentação escolar.

\section{RESULTADOS E DISCUSSÃO}

\section{Análise Documental}

O presente trabalho visou proporcionar uma análise de como o conceito de Soberania Alimentar é tratado no Programa Nacional de Alimentação Escolar de Piracicaba (SP). Sendo assim, apresentar-se-á a análise dos documentos selecionados.

\section{Análise do Documento 1: Resolução no 26, de 17 de junho de 2013, a partir das 5 palavras-chave, a saber:}

"Soberania Alimentar", "Sustentabilidade", "Respeito à Cultura e Hábitos Alimentares", "Alimentos Oriundos de Agricultura Familiar ou Sustentável”.

\section{Palavra-chave: Soberania Alimentar}

A palavra-chave "Soberania Alimentar" não foi explicitamente encontrada no documento. No entanto, pode-se observar que alguns princípios da Soberania Alimentar fazem parte do documento pela evidência de questões que são tratadas por exemplo, nos itens I, II, V e VI presentes e destacados no Capítulo I, Artigo 2 das Diretrizes e Objetivos do Programa, elencados e destacados a seguir:

I - "O emprego da alimentação saudável e adequada, compreendendo o uso de alimentos variados, seguros, que respeitem a cultura, as tradições e os hábitos alimentares saudáveis, contribuindo para o crescimento e o desenvolvimento dos alunos e para a melhoria do rendimento escolar, em conformidade com a sua faixa etária e seu estado de saúde, inclusive dos que necessitam de atenção específica;"
II - "A inclusão da educação alimentar e nutricional no processo de ensino e aprendizagem, que perpassa o currículo escolar, abordando o tema alimentação e nutrição e o desenvolvimento de práticas saudáveis de vida na perspectiva da segurança alimentar e nutricional;"

$\mathrm{V}$ - "O apoio ao desenvolvimento sustentável, com incentivos para a aquisição de gêneros alimentícios diversificados, produzidos em âmbito local e preferencialmente pela agricultura familiar e pelos empreendedores familiares rurais, priorizando as comunidades tradicionais indígenas e de remanescentes de quilombos; e"

VI - "O direito à alimentação escolar, visando garantir a segurança alimentar e nutricional dos alunos, com acesso de forma igualitária, respeitando as diferenças biológicas entre idades e condições de saúde dos alunos que necessitem de atenção específica e aqueles que se encontrem em vulnerabilidade social."

Os itens destacados revelam que as diretrizes e objetivos do PNAE conferem importância à compra $\mathrm{e}$ preparo de gêneros alimentícios que respeitem a cultura e os hábitos alimentares dos beneficiários do programa.

O V item do documento, por sua vez, revela a questão do apoio ao desenvolvimento sustentável, que apesar de ser um conceito amplo e sem definição determinada, se aproxima do desenvolvimento capaz de suprir necessidades atuais, sem comprometer a capacidade de atender as necessidades das futuras gerações [10]. Deste modo, o PNAE se revela um programa que possui em sua essência, a preocupação com a promoção da sustentabilidade, da utilização de recursos de forma consciente e em respeito à natureza, preconizando o desvencilhamento da produção em massa, que esgota recursos e causa danos irreversíveis para a natureza e populações.

Outro ponto interessante se refere às compras de gêneros alimentícios oriundos de agricultura familiar, para que de acordo com a Lei no 11.947, de 16 de junho de 2009, toda a verba repassada pelo FNDE, pelo menos 30\% dela deve ser utilizada na compra de gêneros alimentícios oriundos de agricultura familiar, do empreendedor rural ou suas organizações, priorizando assentamentos de reforma agrária, as comunidades tradicionais indígenas e comunidades quilombolas. 
A gestão do PNAE ao comprar gêneros alimentícios de agricultores promove inúmeros benefícios, dentre eles, contribui para regular o mercado, pois a agricultura familiar é capaz de regular e diminuir os preços dos alimentos e matérias-primas agropecuárias, uma vez que o custo dos alimentos dos trabalhadores é menor, outro aspecto positivo é a transferência de renda para outros setores, pois os agricultores utilizam remuneração mínima de seu trabalho e de seu patrimônio, o que proporciona investimentos em outras áreas de produção, propicia também a segurança alimentar, pois normalmente os agricultores familiares são numerosos e a produção deles é diversificada e como não são capazes de ter um estoque grande, eles acabam por manter a oferta sempre regularizada e diversa.

A agricultura familiar também traz inúmeras vantagens e benefícios ambientais, pois a mesma é alicerçada em princípios que estabelecem uma relação harmoniosa do homem com o meio ambiente. Em uma conjuntura onde a discussão mundial se dá acerca da necessidade de empreender a preservação ambiental para garantir a existência do planeta e das futuras gerações, a agricultura familiar se mostra como excelente alternativa para contribuir para a produção de alimentos saudáveis sem o uso de agrotóxicos, para diminuição dos danos aos solos, causados pelos processos de irrigação das monoculturas, e entre outras práticas sustentáveis de produção.

A palavra-chave "Soberania Alimentar" é um conceito amplo e que abarca múltiplas questões que se entremeiam e muitas vezes torna difícil precisar o que está incluído no conceito ou não. No documento em questão, de um modo geral, pode-se dizer que várias interfaces do conceito de Soberania Alimentar estão asseguradas e fazem parte das diretrizes principais que delineiam o funcionamento do PNAE.

\section{Palavra-chave: Sustentabilidade}

O Artigo 14, da Resolução no 26, de 17 de junho de 2013, referente à oferta da alimentação nas escolas, expressa a única passagem em que o termo Sustentabilidade aparece explicitamente.

Art. 14. Os cardápios da alimentação escolar deverão ser elaborados pelo RT, com utilização de gêneros alimentícios básicos, de modo a respeitar as referências nutricionais, os hábitos alimentares, a cultura alimentar da localidade e pautar-se na sustentabilidade, sazonalidade e diversificação agrícola da região e na alimentação saudável e adequada.

No contexto do Artigo 14, a Sustentabilidade aparece como sendo a forma ideal que a produção agrícola dos gêneros alimentícios destinados aos cardápios da alimentação escolar deve ocorrer.

No entanto, durante a análise da palavra-chave Soberania Alimentar foi observada a presença da noção de Sustentabilidade (desenvolvimento capaz de suprir necessidades atuais, sem comprometer a capacidade de atender as necessidades das futuras gerações), o que revela que implicitamente a ideia esteve representada.

\section{Palavra-chave: Respeito à cultura e hábitos alimentares}

No que tange ao respeito à cultura e hábitos alimentares, o documento analisado apresenta trechos em que os mesmos são tratados como objetivo fundamental para atuação do PNAE, uma dessas passagens, corresponde ao item I do Artigo 2, inserido no Capítulo I que já foi anteriormente citado e que faz referência explícita.

I - "O emprego da alimentação saudável e adequada, compreendendo o uso de alimentos variados, seguros, que respeitem a cultura, as tradições e os hábitos alimentares saudáveis, contribuindo para o crescimento e o desenvolvimento dos alunos e para a melhoria do rendimento escolar, em conformidade com a sua faixa etária e seu estado de saúde, inclusive dos que necessitam de atenção específica;"

Esse item exposto também se mostra como importantes precursores do desenvolvimento local, pois ao se prezar pelo respeito aos hábitos alimentares de uma determinada região, presume-se que seja aquele alimento que é produzido, plantado, colhido e fabricado na localidade, caso contrário, não seria um alimento enraizado naquela cultura. Com isso, haveria enormes ganhos com a compra diretamente dos agricultores familiares.

Em outro momento, a expressão "respeito à cultura alimentar", pode ser vista no item II, do Artigo 12, Capítulo V: 
II - "Planejar, elaborar, acompanhar e avaliar o cardápio da alimentação escolar de acordo com a cultura alimentar, o perfil epidemiológico da população atendida e a vocação agrícola da região, acompanhando desde a aquisição dos gêneros alimentícios, o preparo, a distribuição até o consumo das refeições pelos escolares."

Das ações de educação alimentar e nutricional, no item VI do Artigo 13, há um trecho que revela que as ações desenvolvidas nas escolas, referente à alimentação, devem estimular os hábitos alimentares regionais e saudáveis.

A esse respeito Pipitone [13] já destacou a importância da escola reconhecer e valorizar o espaço pedagógico da merenda escolar. Os estudos sobre alimentos e nutrição podem ser extremamente otimizados se os professores aproveitassem o espaço da merenda e das cantinas escolares como laboratórios de ensino sobre conceitos como acesso aos alimentos, fome e desnutrição, higiene alimentar, origem, fonte e função dos alimentos, propaganda e consumo de alimentos, etc.

Com a análise do item VI que trata do favorecimento de hábitos alimentares regionais e culturais saudáveis, observa-se que a Resolução no 26, de 17 de junho de 2013 não se restringe à operacionalização do PNAE, mas também com a educação alimentar e nutricional praticada nas escolas.

O Artigo 14 é um exemplo dessa afirmação ao destacar prioridade ao respeito aos hábitos alimentares e à cultura alimentar da localidade onde o PNAE estiver inserido:

Art. 14. Os cardápios da alimentação escolar deverão ser elaborados pelo RT, com utilização de gêneros alimentícios básicos, de modo a respeitar as referências nutricionais, os hábitos alimentares, a cultura alimentar da localidade e pautar-se na sustentabilidade, sazonalidade e diversificação agrícola da região e na alimentação saudável e adequada.

\section{Palavra-chave: Alimentos oriundos de agricultura familiar ou sustentável}

A busca pela palavra-chave "alimentos oriundos de agricultura familiar ou sustentável" no texto da Resolução no 26, de 17 de junho de 2013, revelou-se no item V do Artigo 2, capítulo I da seguinte forma:

$\mathrm{V}$ - "O apoio ao desenvolvimento sustentável, com incentivos para a aquisição de gêneros alimentícios diversificados, produzidos em âmbito local e preferencialmente pela agricultura familiar e pelos empreendedores familiares rurais, priorizando as comunidades tradicionais indígenas e de remanescentes de quilombos."

$\mathrm{O}$ item $\mathrm{V}$ também expressou que a aquisição de gêneros alimentícios de agricultores familiares, empreendedores familiares rurais, comunidades tradicionais indígenas e de remanescentes de quilombos é algo que está inserido nos objetivos principais do PNAE. Isto é importante, pois demonstra o potencial que o PNAE tem de promover e fortalecer o desenvolvimento local ao adquirir alimentos oriundos do sistema envolvido na agricultura familiar.

O artigo 24 por sua vez, corresponde especificamente à compra de gêneros alimentícios de agricultura familiar pelo PNAE e mais ainda, estipula a porcentagem mínima de compra, que atualmente corresponde a $30 \%$.

Art. 24. Do total dos recursos financeiros repassados pelo FNDE, no âmbito do PNAE, no mínimo 30\% (trinta por cento) deverá ser utilizado na aquisição de gêneros alimentícios diretamente da Agricultura Familiar e do Empreendedor Familiar Rural ou suas organizações, priorizando os assentamentos da reforma agrária, as comunidades tradicionais indígenas $\mathrm{e}$ comunidades quilombolas, conforme o art. 14, da Lei n ${ }^{\circ} 11.947 / 2009$.

A definição dessa porcentagem mínima é um grande avanço para o PNAE, isto porque, define um modelo que irá trazer resultados positivos e que pode se consolidar e consequentemente crescer.

Análise do Documento 2: Texto de apresentação do PNAE contido na Home Page da Secretaria Municipal de Educação de Piracicaba (SMEP) (www.educacao.piracicaba.sp.gov.br)

\section{Palavra-chave: Respeito à cultura e hábitos alimentares}


Este documento contém todo o histórico, a evolução e as especificidades sobre o Programa Nacional de Alimentação Escolar do município de Piracicaba (SP).

O documento, em uma visão, geral resgata informações baseadas na Resolução no 26, de 17 de junho de 2013. No entanto, dentre as palavras-chave desta pesquisa, a que mais aparece é o "respeito à cultura e hábitos alimentares". Essa palavra-chave aparece no documento em diferentes contextos, como por exemplo, a busca por fornecer alimentos aos estudantes, de acordo com a cultura, tradições e hábitos alimentares, o que garantiria o controle social, segurança alimentar e nutricional e o tratamento igualitário dos escolares com necessidades alimentares especiais.

Em outro momento, o texto cita a formação de hábitos alimentares saudáveis, a partir de ações de educação alimentar e nutricional, além da oferta de refeições que supram as necessidades nutricionais, durante a permanência do aluno em sala de aula no período letivo.

\section{Palavra-chave: Alimentos oriundos de agricultura familiar ou sustentável}

A respeito desta palavra-chave, no documento é reafirmada a garantia pela lei, da compra de no mínimo 30\% de gêneros alimentícios oriundos de agricultura familiar.

No município de Piracicaba, segunda a gerente da Divisão de Alimentação e Nutrição (PNAE), a compra de gêneros alimentícios oriundos de agricultura familiar, corresponde a $41,43 \%$ do total das compras atualmente.

As outras palavras-chave não foram mencionadas, explícita ou implicitamente no documento.

A partir do exposto é possível observar que a Resolução no 26, de 17 de junho de 2013, por se tratar de um dispositivo legal abarca maior número de questões relacionadas às palavras-chave destacadas no texto, além de explicitar maior detalhamento da tratativa desses temas na aplicação da lei. Já pela análise do texto da Home Page da Secretaria Municipal de Educação de Piracicaba (SMEP) nem todas as palavras-chave aparecem explicitamente, mas observa-se que questões igualmente importantes são enfatizadas pelos documentos, por exemplo, o respeito à cultura e hábitos alimentares, apoio à sustentabilidade local através da compra de alimentos oriundos de agricultores familiares, etc.

A análise documental traz alguns avanços no que se refere à indução do tema de Soberania Alimentar no âmbito do PNAE e isso se confirma com as entrevistas feitas com a gerente da Divisão de Alimentação e Nutrição, na qual foi possível verificar que o conceito de Soberania Alimentar é algo incipiente na gestão do PNAE em Piracicaba, posto que, o conceito na maioria das vezes, fica centralizado apenas no discurso dos profissionais que estão inseridos na área da alimentação. Observou-se a necessidade de difundir o tema da Soberania Alimentar para outros setores e outras secretarias da prefeitura municipal, como por exemplo, para a Secretaria de Agricultura e Abastecimento, Secretaria de Educação e Secretaria da Saúde e consequentemente sobre as rotinas e práticas de gestão dessas diferentes secretarias de governo.

Existe ainda a necessidade de difundir o conceito de Soberania Alimentar para além das secretarias e dos profissionais que atuam no PNAE, mas também transmiti-lo para os diretores de escolas, professores, pais e alunos, estes últimos os principais beneficiários do programa.

O maior entrave na disseminação do conceito de Soberania Alimentar no PNAE pode ser atribuído pela falta de consonância entre as secretarias do município, pois atualmente o PNAE está vinculado à Secretaria de Educação, ocasionando uma centralização das decisões no âmbito dessa Secretaria.

A pesquisa também demonstrou existir a falta de integração e alinhamento entre os governos federal, estadual e municipal acerca do tema, pois cada esfera se compromete apenas com suas obrigações e são poucos os projetos e parcerias firmados entre todos em relação ao tema da Soberania Alimentar.

Os dados e observações coletadas apontaram que é necessário transformar a questão alimentar em um tema transversal e intersetorial para que todos possam ser capazes de desenvolvê-lo no cotidiano de suas atividades e que todos reconheçam a importância do mesmo para um melhor desenvolvimento do PNAE. Esse desenvolvimento ocorreria de forma mais 
harmoniosa a partir de novos objetivos e valores, da redefinição de ações, metas e rotinas de trabalho mais afinadas aos conceitos e práticas da Soberania Alimentar.

Em relação aos alunos beneficiários do programa foi possível verificar que existem atividades e projetos relacionados à questão alimentar e educação alimentar e nutricional, porém, quando esses ocorrem sofrem com a falta de continuidade e/ou acontecem apenas em datas comemorativas. Além disso, existe também a necessidade de trabalhar o conceito de Soberania Alimentar vinculado ao PNAE juntamente aos professores e a comunidade escolar, pois faltam projetos de formação continuada nesse campo.

\section{CONCLUSÃO}

As análises realizadas neste trabalho indicam que o conceito de Soberania Alimentar ainda é um tema pouco explorado e inserido no PNAE, principalmente no que se refere à operacionalização e desenvolvimento do mesmo. O tema aparece nos textos oficiais e nos depoimentos dos gestores do programa de merenda escolar, porém a pesquisa revelou que esse conteúdo não se dissemina entre os demais profissionais atuantes e envolvidos no programa, nem tampouco se reflete em novas práticas mais condizentes com os princípios e metas da Soberania Alimentar.

Fica evidente a necessidade de expandir a compreensão do referido conceito a partir da sua divisão em "objetivos e princípios" que devem estar presentes nas diretrizes do programa e, sobretudo, em suas rotinas de operacionalização, tais como: decisão sobre aquisição de alimentos oriundos de métodos sustentáveis de produção, que favoreçam o desenvolvimento de comunidades locais sem agravos ao meio ambiente, respeito aos hábitos alimentares e culturais dos beneficiários e respeito às políticas alimentares. Esses "objetivos e princípios" aqui chamados, impulsionariam um desenvolvimento mais adequado do PNAE frente às demandas de produção e alimentos, pois ao se pensar em esgotamento de recursos, agressão ao meio ambiente, pobreza no campo, entre outros agravantes, o programa pode se tornar um dos grandes viabilizadores da chamada sustentabilidade e se tornar um programa cada vez mais comprometido com essa questão.
Contudo, a quantidade de atores envolvidos na cadeia de desenvolvimento do PNAE se revela como o maior desafio a ser superado no que se refere à adesão do programa aos objetivos e princípios da Soberania Alimentar. Essa verificação tomou por base o fato do PNAE ser um programa complexo, com muita interferência externa o que dificulta a definição de objetivos comuns ao programa; prevalecendo algumas vezes os interesses emergentes, ou ainda, o conflito de interesses.

A restrição orçamentaria é algo que muito influencia na tomada de decisões do PNAE. A prefeitura pode optar por realizar apenas o necessário com relação à merenda escolar ou implantar projetos de melhoramento contínuo de seus processos e produtos relacionados à alimentação escolar. Trata-se de uma decisão política e logicamente uma decisão orçamentária.

Por fim, sugere-se que haja um maior empenho e coordenação entre todos os profissionais, técnicos e gestores envolvidos no gerenciamento e operacionalização do PNAE, pois apesar de boas intenções o programa pode se tornar mais adequado à realidade do município onde está inserido.

\section{REFERÊNCIAS}

[1] Belik W. Perspectivas para segurança alimentar e nutricional no Brasil. Saúde Soc. 2003;12(1):12-20.

[2] La Via Campesina. The international peasant's voice [internet] [acesso em 18 out 2015]. Zimbabwe; 2011. Disponível em: http://viacampesina.org

[3] Maluf R. O novo contexto internacional do abastecimento e da segurança alimentar. In Belik W, Maluf R. Abastecimento e segurança alimentar. Campinas: Unicamp; 2000. p. 37-63.

[4] Siliprandi E. É possível garantir a Soberania Alimentar a todos os povos no mundo de hoje? Agroecol. Desenv. Rur. Sustent. 2001;2(4):16-19.

[5] Almeida Jr. AR, Molina SMG, Martirani LA, Ballester MVR, Garavello MEPE, Verdade LM, et al. Interação interdisciplinar: a experiência da Pós-Graduação em Ecologia Aplicada da USP. In: Philippi Jr. A, Neto AJS. Interdisciplinaridade em Ciência, Tecnologia \& Inovação. São Paulo: Manole; 2011. p. 298-324. 
[6] Nærstad A. The Earth Summit 2012 Should Give Strong Support to Small Scale Sustainable Agriculture [internet] [acesso em 15 jul 2015]. Norway; 2012. Disponível em: http://www.esalq.usp.br/pg/docs/art11_212.pdf

[7] Valente FLS. Direito à alimentação: desafios e conquistas. São Paulo: Cortez Editora; 2002.

[8] Costa EQ, Ribeiro VMB, Ribeiro ECO. Programa de Alimentação Escolar: espaço de aprendizagem e produção de conhecimento. Rev. Nutr. 2001;14(3):225-229.
[9] Pipitone MAP. A relação saúde e educação na escola de 1ㅇ Grau. Rev. Aliment. Nutr. 1995;15(65):48-52.

[10] World Food Programme - WFP. State of School Feeding World Wide [internet] [acesso em 20 jun 2015]. Roma; 2013. Disponível em: http://documents.wfp.org 